\title{
CURQVignettes
}

\section{Research in a Senior/Sophomore Cell Biology Curriculum}

Melville B. Vaughan,

University of Central Oklahoma, mvaughan4@uco.edu

CUR and the Oklahoma IDeA Network of Biomedical Research Excellence (INBRE) co-sponsored a curriculum-reform workshop in November 2012 for Oklahoma faculty at primarily undergraduate institutions. The workshop facilitators provided compelling evidence that incorporating research into the curriculum would be beneficial to all parties. As a faculty member at the University of Central Oklahoma, I had already tested the use of research activities in my senior/ graduate-level molecular cell physiology class (BIO4000) and had decided to gradually change the curriculum over the next few semesters. I also taught a sophomore-level cell biology course (BIO2000) in which students received grades based only on multiple-choice exams. I hoped to include research as part of their grade, but that was challenging because it was a lecture-only course with no teaching assistant. It was clear that to successfully incorporate research and subsequent evaluation into this curriculum I would require assistance. My goal was to use BIO4000 students to mentor the BIO2000 class.

BIO4000 was a five-credit course (three hours lecture, 3 hours lab per week) with a typical enrollment of 12 to 20 seniors and one to four graduate students. The lecture was content-heavy, covering most of the topics from a large cell/ molecular biology textbook. The lab used kits sold by vendors. Students were divided into four-person teams, and each team was responsible for teaching one of the labs. The lead team was required conduct a dry-run of an experiment using a relevant laboratory kit outside of class to learn how to use it and then teach the class how to run the lab during a class session. While the students did not like using their own time, they earned a grade for the work and scored well on tests related to their lab. To facilitate research in this class, I reduced the course material from 80 to 50 percent of the original, in order to cover topics mostly related to research. I replaced the kits with models and assays I run in research (immunostaining, western blots, cell cycle analysis, migration assays), and the students used them to study various aspects of myofibroblast biology. I began with these because they were easy and inexpensive, and I already had purchased the reagents with grant money. I used student course fees to pay for the cases of plastic ware and reagents. I applied for and received an exemption from required IRB approval of research work in the class. I also had a graduate teaching assistant who was already trained to use each of the assays. The teamwork and dry-runs were maintained as before.

Each BIO4000 team member had clearly outlined responsibilities for their own project. All team members were required to read a journal article (at least one review and one research paper per team), participate in experiments, and contribute to a PowerPoint presentation and paper. One remaining team member was required to be the BIO4000 team manager, to compile the team's research reports into a single coherent article, and prepare the PowerPoint presentation based on the written report. Additionally, each BIO4000 team member had a responsibility to mentor a BIO2000 team, either through direct mentoring or evaluation of the BIO2000 team's output. Each BIO4000 team was required to provide one or two members to work as peer-mentors for BIO2000 student teams. Each mentor provided his/her BIO2000 team a previously collected BIO4000 dataset generated using the assay of the mentor's expertise, and the mentor was expected to answer questions on a limited basis. BIO4000 members who were unable to directly mentor $\mathrm{BIO} 2000$ teams were required to grade BIO2000 PowerPoint presentations and written reports (described in the BIO2000 section below).

Any extra members were required to provide a written script for the mentors to facilitate their interaction with the BIO2000 team and prepare the BIO4000 PowerPoint. A team of three to five students could handle this amount of work. Smaller teams were given easier/faster assays to run. The first 75 percent of the labs consisted of team-led instruction on the assay methods. For the last 25 percent of the labs, each team used its assay expertise to test a hypothesis; in this case, all the teams tested the same chemical's effect on myofibroblasts. The last week of class the teams gave their presentations and turned in a manuscript. The students were also asked to write a reflection about their experience; this was particularly important for team members who interacted with the BIO2000 students.

BIO2000 was a lecture-only, three-hour course with 30 to 40 students. The Biology I prerequisite provided enough background to enable me to replace traditional content with research. I assembled the teams about halfway through the semester. BIO4000 mentors came to class and were introduced to the groups at that time. We used another classroom to separate the groups to reduce the conversational noise. The peer mentors described their class projects and gave the teams their datasets and duties. Each BIO2000 team had a month to find articles and analyze the data. During the last week of class each group gave an oral presentation and turned in a group report. All the peer mentors were present for the team reports and were asked to provide feedback 
on all the presentations. The BIO4000 teaching assistant compiled the team reviews and submitted them to the peer mentors, who in turn shared the reviews with their BIO2000 teams. Team members evaluated each other and submitted a "percent effort" sheet that was used by the instructor to assist with fair grading.

The university's assessment office surveyed students regarding their evaluations of BIO4000 and BIO2000. On a scale of 1 to 5, BIO2000 students' evaluations were in the 3 to 4 range; students were willing to replace lecture content with the team project but unwilling to trade a grade from a series of online quizzes with the grade for their team's project. BIO4000 students' evaluations of the class were in the 4 to 5 range; these students were less willing to replace the narrow content with a broad-based curriculum and to participate in the lecture. The students rated most of the activities favorably; they appreciated being graded for skills and tasks unrelated to recalling facts. BIO4000 students reflected that they were more serious, scholarly, and teamwork-oriented than when they were BIO2000 students.

Later I was able to recreate the peer-mentoring for BIO2000 using upper-class and graduate research students rather than a BIO4000 class, with similar results. Some BIO2000 students reported poor experiences with the peer mentors, suggesting that training of peer mentors may be necessary. BIO4000 class members provided follow-up experiments for future classes. This model should be useful for faculty who desire to maintain a research program while teaching full time and providing university service. University commitment through student assistantships and lab support is beneficial.

I would like to acknowledge Heather Rabalais for the assessment materials, James Bidlack for providing the dry-run teamwork concept for the BIO4000 labs, and Robert Brennan for helpful comments and suggestions.

\section{doi: $10.18833 /$ curq/37/1/16}

\section{Course Scaffolding for Research Practicums}

David Lonzarich, Evan Weiher, Ruth Cronje, Jessica Kraker, University of Wisconsin-Eau Claire, lonzard@uwec.edu

A common problem in the sciences is the growing student demand for research experiences and growing faculty anxiety concerning meeting this demand. The demand has been fueled by knowledge that undergraduate research is considered a high-impact teaching and learning practice by such entities as the Association of American Colleges and Universities (https://www.aacu.org/resources/high-impact- practices). While many campuses, including the University of Wisconsin-Eau Claire, provide opportunities for extracurricular undergraduate research (in summer research projects, for example), only small numbers of high-achieving students tend to have access to these opportunities. Less common are mechanisms providing this high-impact experience for larger numbers of students of more modest academic achievement within the regular curricular context. We have been experimenting with an integrative course and research program that offers an authentic research experience to students enrolled in our regular biology curriculum.

The American Association for the Advancement of Science has articulated science literacy goals for the science curriculum at both the $\mathrm{K}-12$ and the undergraduate levels (http://www.project2061.org/publications/articles/2061/ sfaasum.htm). Three dimensions of scientific literacy have informed our curricular innovation at UWEC: understanding key concepts and principles; understanding scientific inquiry and ways of thinking; and understanding how science is influenced by and influences human social, economic, and political activity. The program has involved four faculty members from three college departments (two faculty members in biology, one in mathematics, and one in English). The goal has been to enhance students' scientific literacy on all three dimensions.

Five years ago, students at UW-Eau Claire provided funds to support a hybrid curriculum and research program for students in biology. We are now in our fourth cohort of students, and the program has been by all measures an incredible success. Our cohorts have each consisted of 18 to 20 biology students. Recruited as sophomores, these students begin their journeys with a research-methods course, during which they are introduced both to scientific inquiry and to the research projects of their biology mentors. After choosing their research mentor in the first semester, students move into one of two courses (one in math and one in biology) to develop quantitative skills that they will use in their research. Their research occurs during the following summer and fall (with associated coursework in the fall) and culminates in the second year with a course in which students are given instruction in scientific argumentation, including an experience with the peer-review process. Students write an NSF grant proposal to seek funding for the next logical step in the research projects they have been involved in. This course also offers students the opportunity to participate in discussions regarding scientific ethics (including scientific misconduct and the use of human and animal subjects in research). This program offers a sustained experience that better mimics the authenticity and multidimensionality of a scientific career than a single course can. 